\title{
The Determinants of Intra-Group Relationships in the Longitudinal Research of Training Group
}

\author{
Ekaterina Ivanovna Kolesnikova $^{1} \&$ Tatiana Vyacheslavovna Kolesnikova ${ }^{1}$ \\ ${ }^{1}$ Samara State University of Architecture and Civil Engineering (SSUACE), Samara, Russian Federation \\ Correspondence: Kolesnikova E. I., Molodogvardeyskaya, St., 194, Samara, 443001, Russian Federation
}

Received: February 28, 2015 Accepted: March 20, 2015 Online Published: April 24, 2015

doi:10.5539/res.v7n6p108 URL: http://dx.doi.org/10.5539/res.v7n6p108

\begin{abstract}
The article presents the results of a study of the determinants of intra-group relations on the example of the relationship sociometric indexes with the personal qualities and values, the level of intellectual development. A group of students is considered as the environment of the development of the individual student and the formation of its competence. In a longitudinal study it was received that the aspiration of the student to the joint activity affects the formation of his personal values and qualities and are correlated with the recognition in his training group. The seriousness, the dominance and the development of thinking affect the preference of students learn together with the student (sociometric status), which increases his self-control. Sex and intergroup differences in the determinants and the relationship are not installed.
\end{abstract}

Keywords: student, personal development, values, sociometry, intra-group relations

\section{Introduction}

Today the renovation of higher education is based on the competence approach. It means that along side with professional knowledge and skills students develop their active attitude towards themselves and the world around. Therefore the enhanced attention as to individual and group subjectness of students is natural. A special place belongs to research of intra-group relationships in student group as an environment where educational interaction is interpreted and professionalization becomes positive or negative. Intra-group relationships mean relations which formed during students' individual and group educational activity during their training in high school purposefully organized to provide their psychic, personal and professional development.

Theoretical and practical questions brought up by the study of educational community have a long history. Following the didactic aspects of education (Diesterweg \& Komensky) and the research of student groups (Lektorskiy, Makarenko, \& Rokov), today scolars study the problems of functioning of group as a group subject and a collective subject (Zhuravlyov), revealing itself at such levels as cognition (Andreyeva \& Yakunin), activity (Vygotskiy, Davydov, Zimnyaya, Petrovskiy, \& Chernyshov) and emotions (Kolominskiy, Markova, \& Rean).

Various problems were accentuated in the structure of intra-group relationships. For instance, relationships in student group and their influence on the formation of student's personal qualities were actively studied by V. T. Lisovskiy and N. M. Peysakhov (Lisovskiy, 1974; Peysakhov, 1979). The results of their study became a basis for applied psychology in high school. In their research, they tried to ascertain first of all what relationships promote to students' cognitive activity during classes and what factors determine the formation of such relationships. Among these factors, the scolars mark out the level of cognitive activity, the features of valuable orientation and motivation to learn.

From the viewpoint of the system-activity approach, A. V. Petrovskiy studied the determination of relationships more generally: as relationships are formed during activity, their structure and psychological mechanisms can be studied only by analyzing the features of activity and features of cognitive activity as the prevailing one among students (Petrovskiy, 1979, 2011).

At the same time, G.M. Andreyeva marks that it is not enough to consider only the presence of many people surrounding a person and interacting with he in specific situations (Andreyeva, 2006). The content characteristic of the activity of a group and subjects included in it is important, especially in real groups.

From the viewpoint of the subject-activity approach (Abul'khanova-Slavskaya, Brushlinskiy, \& Rubinshtein), 
the psychological relationships of activity subject are a substantial socio-psychological regulator of activity. A. L. Zhuravlyov and V. P. Pozdnyakov studied the correlation of internal and external conditions, objective relations a man enters into, his subjective attitude to reality and how his attitude determines his activity. The scolars consider external conditions apprehended and estimated by a subject as factors that determine his social behaviour. Then they consider man's psychological attitude to these conditions as the socio-psychological mechanisms of this determination (Zhuravlyov et al., 2008). Besides, they consider such external conditions as a multilevel formation including both macro environment conditions (socio-economic situation in the country and region, economic policy pursued by government and local authorities) and microenvironment conditions (organizational and economic conditions in a certain enterprise or a work team, socio-economic situation in the family, etc.) (Zhuravlyov et al., 2011). A. L. Zhuravlyov considers that the socio-psychological relationships of subjects should be analyzed both at intra-group and inter-group levels. In the latter case, the subjects of relationships are considered mainly of all as the representatives of some social groups interconnected by joint activity (or, more generally, joint life activity) (Zhuravlyov et al., 2008).

A. V. Sidorenkov analyzed subjective relationships of different level (individual-individual, individual-subgroup, individual-group, subgroup-subgroup and group-subgroup). The scientist emphasizes the interconnection of interactions and relationships. He developed a microgroup concept which considers individuals, groups and subgroups as the subjects of interactions (Sidorenkov, 2012). He concluded that the phenomena of relationships in a group have a complex structure. Besides, he emphasizes that it is very important to analyze in details how some kinds, components and levels of these relationships influence the effectiveness of a group. Relationship phenomena, for example - the levels and types of confidence the levels and components of identity — appeared to be closely interconnected in the determination of group effectiveness (Sidorenkov et al., 2014).

Various sociometric techniques are used in the majority of modern studies of student groups. This seems to be quite logical because "in the act of choice person manifests itself holistically... in the unity of emotional, spontaneous and socially determined, situational" (Kolominskiy, 2001).

The actualization of status structure of interaction between an individual and a group is studied by the socio-psychological mechanism of subjectness formation. Student's high sociometric status in a group is the leading determinant of personal identity (Nesterenko, 2000) and promotes social boldness, courage, communicability and managerial abilities (Dobina, 2011).

Pedagogics speaks more about the formation of intra-group relationships in a study group to increase student's sociometric status. This is promoted by teacher's influence, for example through the development of person's cognitive, emotional and regulating components (Ferapontova, 2001) or through students' curricular and extracurricular work (Sergeychik, 2004).

The author ascertained the role of intra-group relationships in a student group among the psychological determinants of student's subject competence for junior and senior courses (Kolesnikova, 2010). Sociometric status in joint training is included as a predictor in the regression models of forming both final evaluation (state exam and defence of final work) and intermediate evaluation (academic performance index) of student's competence (Kolesnikova, 2014). The author detected (Kolesnikova, 2014) that during joint educational interaction (for example, group laboratory work) students in high-effective learning teams have a higher status in joint training, according to the sociometric survey, and belong to the same microgroups. Among those who were expelled in the first examinations, $87 \%$ of students had a negative sociometric status in joint training (Kaptsov, 2003).

These data are the result of the psychological monitoring of educational process which had taken place in our university since 1996. Today it is carried out with in compliance with the departmental task for high school (Research Project \# 553 "Psychological determinants of student's competence in higher educational institution"). The monitoring covers cognitive, personal, value-motivational and socio-psychological characteristics which influence the competence of students in university.

A large-scale research of relationships in groups were conducted under scientific school headed by Ya.L. Kolominskiy. Concentrating on students' status characteristics, he considered the act of sociometric choice as a result (choice or rejection) of collating specific objects of choice with the reference patterns. Student's position in a group depends on perceived qualities and value system presented in socially important reference set (Kolominskiy, 2001). Ya.L. Kolominskiy notes that the content of reference patterns and stereotypes depends on the age of students under test, their personal experience of relationships and communication, group norms and traditions and also the values of wider environment.

A. V. Kaptsov in his studies found out that sociometric choice is determined by value system. The generality of 
personal values defined as a distance in the multifactor space with the help of cluster analysis is interconnected with the characteristics of small groups. It explains up to $60 \%$ of dispersion in mutual sociometric preferences. Kaptsov connects sociometric cohesion and value compatibility in student group and emphasizes higher similarity of personal values, the higher such sociometric indexes as expansiveness and choice reciprocity (Kaptsov, 2011). In general we can see that empirical approaches are focused on the interconnection of sociometric indexes with various personal qualities, behavioral features, success in certain kinds of activity, less with personal values and the features of group under test.

In another research, A. V. Kaptsov gives a different way to interpret the coefficients of causality for sociometric choice (Kaptsov, 2009). With the help of a method of mathematical treatment for the results of sociometric poll proposed by V. I. Paniotto, Kaptsov detected the causality of answers concerning joint training and recreation of students. For example, the sociometric choice of joint recreation of first-year students is determined by the choice of joint training. Second-year students show the opposite picture. The choice of joint recreation and training of third-year students is interdepended.

\section{Methods}

There are many studies covering intra-group relationships of students. Nevertheless the question of their determination is still explored insufficiently today. The longitude character of student contingent is also studied poorly. This caused the target of our research - to study intra-group relationships in students' group in the course of training in high school.

The hypothesis of our research supposes that intra-group relationships expressed in such students' sociometric indexes as status and expansiveness are determined by their personal qualities and values. Students differ by these qualities and values according to how their attitude to group mates changes in the course of training.

The longitude research was carried out in 2009-2014 on one and the same students of four study groups at the Faculty of Engineering in a technical university. The losses of participants were 14\%. Taking into account the reliability, the psychodiagnostic results of 63 people (39 of them were boys) were approved.

The general level of intellectual ability (Rv) was studied with the help of Raven's progressive matrices (black-and-white version with time limit). Personal qualities were studied using method ANL 4.2 (Kaptsov, 2011) where values are considered in such life spheres as profession, education, family, social activity and hobby. The set of values includes individual and group values, and also the values of traditions, creativity, success, relationships, spiritual satisfaction and material wealth. The great advantage of this method is the scale of reliability (social desirability) which allows discarding test results that give rise to doubt.

An important problem is to increase the objectivity of sociometric indexes by weakening the reasons that distort the determination of choice. For example, Kolominskiy sees among these reasons the age of students, the number of allowed choices, the degree of acquaintanceship of members, the content of group activity and the character of sociometric criterion (Kolominskiy, 2001). We think that the age of students who took part in this research (young adulthood) demands to eliminate various restrictions and to give freedom detecting the features of relationships. Thus we chose a non-parametric (without choice limits) form of sociometric poll. The primary poll was carried out two months after the group was created when the stage of acquaintance is already finished. The repeated poll was carried out at the beginning of the last term when there is still a need and urgency of communication and interaction with group mates as a basis for choosing a partner for joint activity.

As for the question of sociometric criterion, it should be noted that the strongest criteria deal with long-term and wide activity which is important and essential for a person under test. That is why we carried out the poll both for a situation of joint training ("With who of your group mates you would like to perform a task?") and for a situation of joint recreation ("With who of your group mates you would like to rest?") as an important life sphere of the group. In order to increase the reflection adequacy of real relationships in the group, we used negative criteria ("With who of your group mates you would not like to perform tasks?" and "With whom of your group mates you would not like to rest?") which make the structure of relationships more exact.

A computer program was developed to calculate sociometric indexes (Visual Basic for Applications, T. V. Kolesnikova). We calculated the indices of expansiveness (PEU-positive, OEU-negative, EU—general in joint training; $\mathrm{PEO}$ - positive, OEO — negative, EO — general in joint rest) and sociometric status (PSU—positive, OSU—negative, SU—general in joint training, $\mathrm{PSO}$ - positive, OSO — negative, SO — general in joint rest).

The primary and repeated researches were carried out in a group form. A favourable emotional atmosphere was provided. Students had no time limits for questionnaires (with the exception of Raven's progressive matrices). Each of the students under test had his own questionnaire. The discussion of questions among students was not 
allowed. Usually both primary and repeated poll lasted for 1-1.5 hours.

The Mann-Whitney test and one-way ANOVA test were used to detect the differences by sexual dimorphism and analyzed indexes between. The interconnections between sociometric indexes and personal qualities and values were detected with the help of Spearman rank correlation analysis; package STATISTICA 6.0, s/n 31415926535897.

The reliable absence of differences by tested characteristics including sex assignment was detected and made it possible to unite student groups in one sample. Unfortunately, the volume of this sample is not enough to use the method of structural equations which is the most suitable if we want to detect the determinants of multidimensional psychological phenomena. Thus we used the method of cross-deferred correlation (Kornilova, 2002). The calculation of changes in links between variables A and B measured on one and the same students through one and the same time by this method will help us to answer the question what cause-effect relation is the strongest one.

\section{Main Part}

Suppose variable A designates the results of expressed personal qualities and values and the general intellectual level; variable B designates sociometric indices. Index 1 designates the results of the first measurement, and index 2 designates the results of the second one. Then A1B1 is the links between variables in the first measurement, and $\mathrm{A} 2 \mathrm{~B} 2$ is the links in the second one and so on. Table 1 contains an example of analyzed results for variable $\mathrm{B}$, for example for positive status in joint training PSU.

Table 1. Interconnections between variables A and B acc. to Spearman, a fragment (cross-deferred correlation)

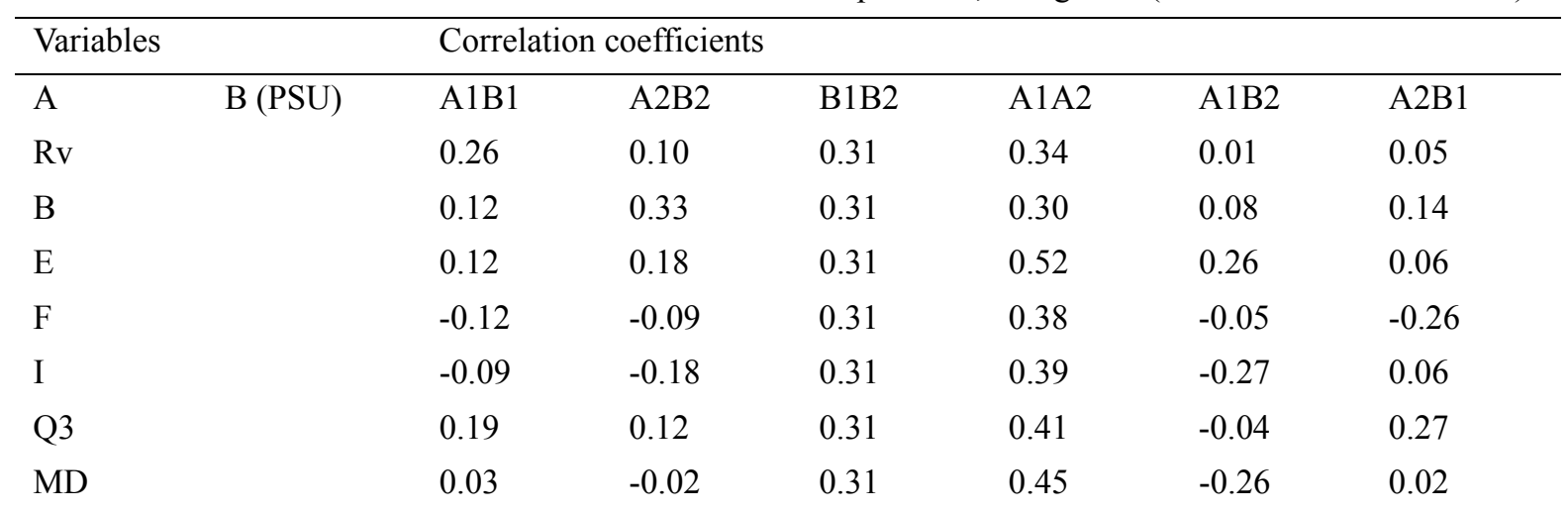

Discription: Coefficients with $\mathrm{p}<0.05$ are in bold type.

As Table 1 shows, the striving of first-year group mates for joint task performance with some student is connected with his high general intellectual level, and in the fifth year it is connected with his quick-wittedness. There was no determination detected between these variables, although students' desire to perform tasks together has an intellectual nature through the whole period of study.

It was detected that student's status in training is determined by his personal qualities: the more student is dominating, stern and the more adequate his self-appraisal is the more the desire of his group mates to perform tasks with him. This desire of his group mates makes the student be more serious and increase his self-control. Most likely, these regularities are connected with students' future professional activity in the field of civil and industrial construction where the listed qualities are very important. At the same time, we see that relationships in the group influence the students positively. This emphasizes once more that it is important not only to analyze relationships in a group but also to conduct a special work aimed at forming a favourable socio-psychological environment in student groups.

It seems impossible to present all the results because of bulky calculations. Figure 1 shows a general idea about relationships in the group.

Figure 1 shows the interconnections and determinations of studied variables both at one time interval and in longitude during the study at the university.

In first-year groups, the preferences of students concerning joint activity with their group mates are more diverse. As we see, student's striving for joint training is connected with the striving for joint recreation and also with 
their statuses in these kinds of activity both at the first and the fifth course. Such richness of links accentuates the necessity to attract attention to social and psychological mechanisms that work in student group from the very start of its existence and to the community of their interests and values. The social-approval need and student's dependence on his group ( $\mathrm{Q}^{-}$factor) increases if there is a desire to study and rest together with group mates. This raises the values of life spheres and personal values. So the peculiarities of group relationships determine the personal development of first-year students and strengthen the importance of both humanistic principles (creativity, relationships) and pragmatic values (achievements, material welfare).

The desire of first-year students to study and rest together is connected with the recognition of group mates and indirectly influences the development of such professionally important qualities as tranquility and self-control. Such students have an adequate self-appraisal which is important for the formation of student's competence.

It should be noted that, in spite of the first year of study, the recognition of group mates among fifth-year students is not connected with student's expansiveness neither in study nor in recreation. Probably the determinants of expansiveness have different reasons not covered by this research. Most likely it is connected with the fact that the common values of first-year students promote adaptation. As students grow older, their values can change and become different but this is not so significant for joint activity as personal qualities.

In order to study the differences of personal qualities among students whose attitude to group mates changed differently, we divided the sample into three subsamples: the index went down in the course of study (the attitude worsened); the index did not change (the attitude remained the same); and the index increased (the attitude became better). We detected differences between subsamples with the help of one-way ANOVA test with reliability assessment by Sheffe's test. 


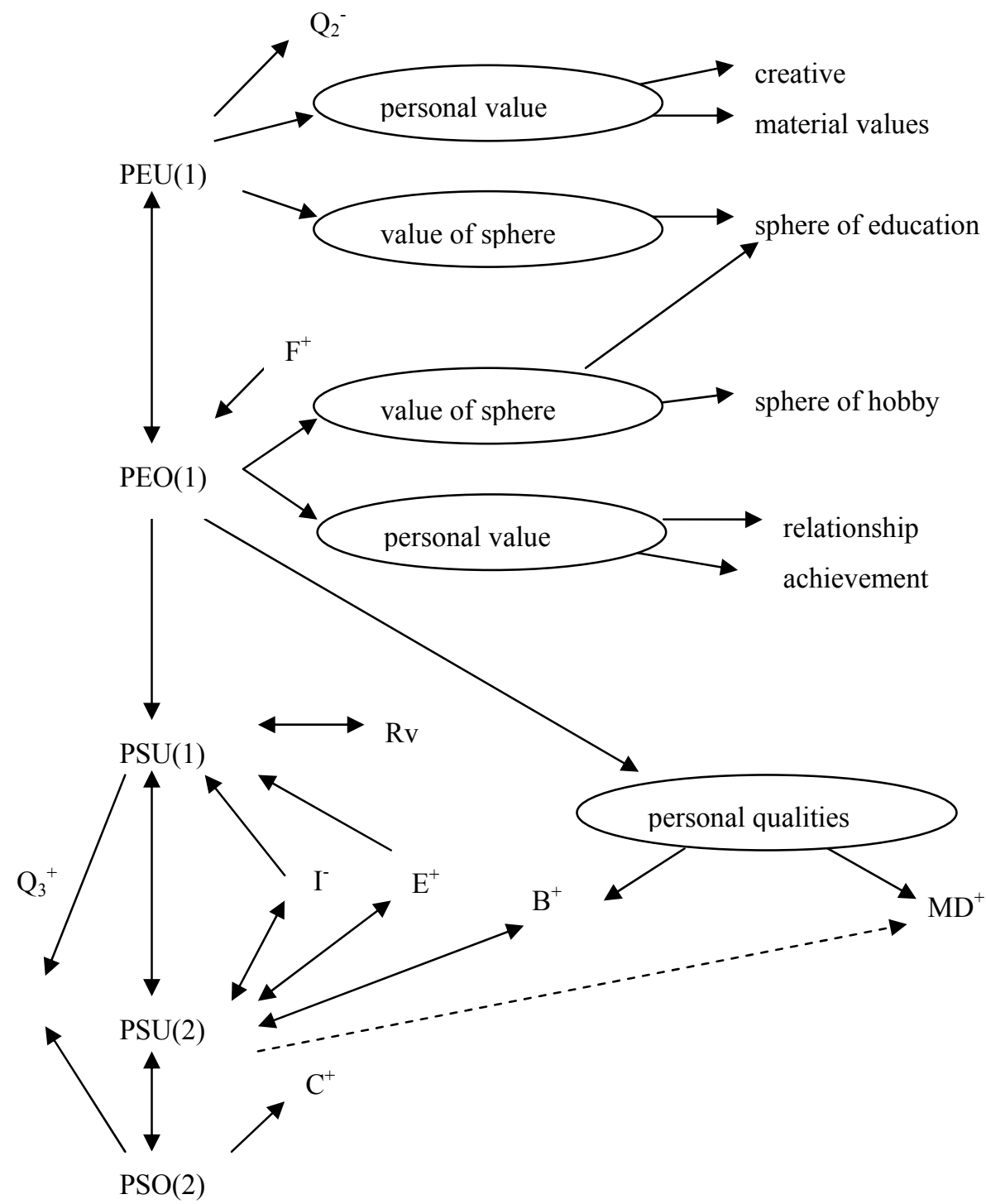

Figure 1. The determination of sociometric statuses by personal qualities and values in the course of study at high school

Discription: Arrows designate the direction of determination-interconnection-the inverse connection of analyzed characteristics. The length of arrows does not mean the force of connection. Figures in brackets designate the order of measurements: 1-measurement in 2009, 2-measurement in 2014. Diacritical marks show the intensity of personal factor pole by Cattell's questionnaire ("+" is for high values, "-" is for low values).

Sexual differences were not detected. Probably this is because of those special girls who chose technical "men's" professions and are influenced by conditions in technical university.

We should note the differences in how the attitude to group mates changes in dependence of volitional characteristics: students with high self-control (Q3 factor) have stable preferences in joint training (PEU, F=3.9 if $\mathrm{p}=0.02$ ), and students with high norm-control ( $\mathrm{G}$ factor) do not change their preferences in joint recreation ( $\mathrm{PEO}, \mathrm{F}=5.1$ if $\mathrm{p}=0.01$ ). Most likely, this is a special kind of people with volitional characteristics are accompanied by a certain rigidity in relationships, and they do not like to change their opinion about other people.

Brave reckless students show growing unwillingness to study with group mates (OEU) (H factor, $\mathrm{F}=4.6$ if 
$\mathrm{p}=0.01$ ). However, this is not surprising. Probably, at the beginning of their study such students insignificantly rejected joint task performance with group mates, then during study the ability to say "no" increased, and they began treating their group mates more critically.

It is interesting that the desire of a group to reject some members of the group (OSU) is interconnected with students' conformism ( $\mathrm{Q}^{-}$factor, $\mathrm{F}=3.9$ if $\left.\mathrm{p}=0.02\right)$. It turns out that independent self-sufficient group mates with their own opinion enjoy recognition among senior students. That is this personal trait (conformism) plays a double role in the relationship of a group and a person during education: it promotes the adaptation of junior students and has a direct connection mediated by expansiveness with recognition in group; and everything is vice versa for senior students.

Recognition in group in joint recreation ( $\mathrm{SO}$ ) does not change for tranquil students ( $\mathrm{C}$ factor, $\mathrm{F}=4.9$ if $\mathrm{p}=0.01$ ) and increases for impulsive and careless students ( $\mathrm{F}$ factor, $\mathrm{F}=3.5$ if $\mathrm{p}=0.03$ ). Thus it is obvious that the stability of personal qualities is interconnected with the stability of relationships in group.

\section{Findings}

The results obtained completely reflect the unity of education, training and development (acc. to Rubinshtein). Moreover, education and training are carried out both in the sphere of studies and outside it (the sphere of leisure). The fact that students reveal their personal qualities and values in subject relationships between person and group touches upon with the principal problem of educational psychology - the correlation of training and development. We see the role of group relationships in the personal development of students. This development continues throughout the whole study at university. In this case, intra-group relationships become a factor of personal and professional self-determination and a part of "the subjective picture of professional world" (Akopov). The way these relationships are organized should be influence the purposes of education and training technologies, especially interactive ones (Akopov \& Gorbacheva, 2003; Kolesnikova, 2011).

Both personal and value characteristics were detected among the determinants and interconnections of sociometric indexes of first-year students. By the end of study, the more significant presence of personal structures was stated. It should be noted that leading trends have a socially desirable tint (towards the development of professionally important qualities). It seems interesting to continue the research in student groups with negative trends to achieve the complete understanding of social and psychological determinants of educational process in high school.

Unfortunately, today the developing potential of student group is not enough used in high school. The socio-psychological problems of training competent specialists are little-studied. That is why the findings obtained by this research can be useful for the applied socio-psychological problems of education and the questions of pedagogical psychology in high school. They can especially help to analyze the results of adopting the general educational program from the viewpoint of favourable environment for the formation of necessary psychological qualities.

\section{Acknowledgements}

The authors thank prof. A.V. Kaptsov and Iu. S. Vasilieva for the assistant in writing this paper. The research is carried out within the framework of the departmental task for high school (Research Project No.553 "Psychological determinants of student's competence in higher educational institution").

\section{References}

Akopov, G. V., \& Gorbacheva, A. V. (2003). The Social Psychology of Student as a Subject of Educational Process: Monograph (pp. 181-183). Moscow: Mashinostroyeniye.

Andreyeva, G. M. (2006). Social Psychology (p. 363). Moscow: Aspect Press.

Dobina, N. I. (2011). The Psychological Structure of Proneness to Conflict among Students with Different Sociometric Status (PhD Thesis). Yaroslavl: YaSU.

Ferapontova, O. I. (2001). The Formation of Intra-Group Relationships of High School Students in the Course of Training (PhD Thesis). Samara: SSU.

Kaptsov, A. V. (2003). The Psychological and Pedagogical Support of Multi-Level Higher Education: Monograph (pp. 222-223). Samara.

Kaptsov, A. V. (2009). The Detection of Reasons in Sociometric Research. The Review of Samara Academy of Humanities. Series "Psychology", 2(6), 164-171.

Kaptsov, A. V. (2011). Personal Values as a Characteristic of Compatibility in Student Groups. The Scientific 
Notes of the Trans-Baikal State University. Series: Pedagogic and Psychology, 5, 190-194.

Kaptsov, A. V. (2011). The Psychological Axiometry of Person and Group (p. 7). Samara: SamLuks Print.

Kolesnikova, E. I. (2010). The Monitoring of Student's Socio-Psychological Competence in High School. Izvestiya RAS, 12(3), 726-729.

Kolesnikova, E. I. (2011). The Social and Psychological Features of Joint Educational Interaction of High School Students. The Social Psychology of Small Groups: the Proceedings of the Second All-Russian Research and Practice Conference (pp. 368-371). Moscow: MSPPU.

Kolesnikova, E. I. (2014). The Psychological Determinants of Student's Subject Competence. International Journal of Science and Research, 7(26), 79-83.

Kolominskiy, Y. L. (2001). The Psychology of Relationships in Small Groups (p. 432). Minsk: TetraSystems.

Kornilova, T. V. (2002). Experimental Psychology: Theory and Methods (pp. 108-109). Moscow: Aspect Press.

Lisovskiy, V. T. (1974). Contemporary Student. The Social Psychology of a Person (pp. 125-139). Leningrad: LSU.

Nesterenko, N. A. (2000). The Influence of Status Structure of Interaction between an Individual and a Community on the Personal Subjectness of Senior Pupils in Elective Education (PhD Thesis). Kursk.

Peisakhov, N. M. (1979). Applied Psychology in High School: Multi-Authored Monograph (p. 270). Kazan: KSU.

Petrovskiy, A. V. (1979). The Origin and Essence of the Stratometric Approach in Collective Psychology. In The Psychological Theory of Collective (pp. 20-43). Moscow: Pedagogika.

Petrovskiy, V. A. (2011). Activity Mediation in Interpersonal Relationships: Phenomena, Essence. Social Psychology and Society, 1, 5-16.

Sergeychik, T. S. (2004). The Formation of Interpersonal Relationships in Student Group: On the Example of a Technical University (PhD Thesis). Kemerovo: KSU.

Sidorenkov, A. V. (2012). The Social Psychology of Small Groups: Tutorial (p. 381). Rostov-on-Don: Fenix.

Sidorenkov, A. V., Sidorenkova, I. I., \& Ulyanova, N. Y. (2014). The Socio-Psychological Characteristics and Effectiveness of Small Groups in an Organization: Monograph (p. 248). Rostov-on-Don: MiniType.

Zhuravlyov, A. L., \& Kupreychenko, A. B. (2011). The Psychological and Socio-Psychological Space of Person and Group: The Understanding, Kinds and Trends of Research. Psychological Journal, 32(4), 27-37.

Zhuravlyov, A. L., Pzdnyakov, V. P., \& Titova, O. I. (2008). The Psychological Attitude of Russian Businessmen to Competition and Partnership: The Gender Aspect. Science-Culture-Society, 4, 102-115.

\section{Copyrights}

Copyright for this article is retained by the author(s), with first publication rights granted to the journal.

This is an open-access article distributed under the terms and conditions of the Creative Commons Attribution license (http://creativecommons.org/licenses/by/3.0/). 